\title{
The Effect Of Social Cognitive Theory-Based Psycho- Education Towards Depression And Blood Pressure Of Ischemic Stroke Patients
}

Tata Mahyuvi', Nursalam ${ }^{2}$

${ }^{1}$ Nurse, Islamic Surabaya A.Yani Hospital

${ }^{2}$ Professor of Nursing, Airlangga University

Email:

mahyuvi1922@gmail.com

Received: October 5, 2020

Accepted : November 29, 2020

Published : November 30, 2020

\begin{abstract}
Stroke places on the third rank in the world as the cause of death. Depression is a common psychology condition found in ischemic stroke patient and generally experienced hypertension. The aim of this research is to analyze the effect of social cognitive theorybased psycho-education towards depression and blood pressure of ischemic stroke patient. The design of this research is quasiexperiment by pre and post control group within. The population is 100 ischemic stroke patients in mental hospital Jemursari Surabaya, while the samples are 32 respondents. The sampling technique used is simple random sampling. The intervention group was given social cognitive theory-based psycho-education for 1530 minutes in 4 times session and the control group was given intervention as hospital standards. The data were analyzed by paired t-test with significant value $\alpha=0,05$. The result of the research revealed that there was a significant effect between depression and blood pressure before and after the treatment of social cognitive theory-based psycho-education. It shown that depression intervention group $\mathrm{p}$ value $=0,000$ and systole and diastole $p$ value $=0,000$. Social cognitive theory-based psychoeducation was effective to decrease depression and blood pressure of ischemic stroke patient and it is highly recommended for the patient in the rehabilitation phase.
\end{abstract}

Keywords: Psycho-education, ischemic stroke, depression, blood pressure

Copyright (C) 2020 IIK STRADA Indonesia All right reserved.

This is an open-acces article distributed under the terms of the Creative Commons Attribution-ShareAlike 4.0 International License.

\section{INTRODUCTION}

Ischemic stroke occurs as a result of obstruction or blockage in the flow of blood vessels by atherosclerotic plaques, blood clots or a combination of the two which inhibits blood flow to certain areas of the cerebral blood vessels so that one of them impacts on frontal lobe damage (Jauch et al., 2013). Ischemic stroke also causes ongoing problems in the lives of sufferers, including biological, psychological and spiritual changes so that comprehensive nursing care is needed (Dewi \& Darliana, 2017). Psychological problems that arise in ischemic stroke sufferers are experiencing depression, anxiety and deep stress characterized by a fear of pain, fear of disability, fear of death, fear of losing personal independence and loss of role function (Hidayati \& Violita, 2015). 
Stroke ranks third place in the world as a cause of death. More than 2,000,000 people experience a stroke and increase by 6.7\% each year. WHO data (Word Health Organization) in 2011 the number of stroke patients in America each year amounted to 795,000. A total of 610,000 patients were the first stroke and the remaining 185,000 were recurrent strokes (Jauch et al., 2013). The 2010 Global Burden Disease data of all stroke patients in the world as many as $80 \%$ had an ischemic stroke and the remaining $20 \%$ had a hemorrhagic stroke (AHA, 2015). Data on stroke incidence in Indonesia in 2013 were 1,236,825 patients and in 2018 increased by 10.9\% (Riskesdas, 2018). Stroke in East Java Province ranked number three in Indonesia, reaching 302,987 patients. Data on stroke patients in Jemursari Islamic Hospital Surabaya in 2018 amounted to 554 patients consisting of 451 (81.4\%) experiencing an ischemic stroke and 103 (18.6\%) experiencing a hemorrhagic stroke (Data from Jemursari Islamic Hospital Surabaya, 2019).

Depression is a disease that affects the physical, feeling (mood) and mind which is indicated by loss of energy and motivation, feelings of guilt, difficulty in concentration, decreased appetite and the emergence of thoughts of death so that it can be a very serious problem if ischemic stroke does not get serious treatment and appropriate intervention. Factors that cause depression in ischemic stroke patients include biological, genetic and psychosocial factors for instance: loss of real or imagined attachments, such as loss of one's love, physical function, position or self-esteem, changes in roles and economic burdens. Depression is caused by the uncertainty of the future and fear of death (Kaplan \& Sadock, 2015)

Based on the results of the study (Hayulita \& Sari, 2014) about factors related to depression of post-stroke patients in the outpatient room of the Bukittinggi National Stroke Hospital (RSSN) showed the incidence of depression in stroke patients from 52 patients, $61.5 \%$ experienced depression. The same results were also obtained from the study (Guntur \& Maria, 2017) about the relationship of family roles with depression levels in stroke patients who stated out of 96 patients, 46.9\% experienced mild depression, 39.6\% moderate and $13.5 \%$ experience a level of severe depression. Based on the research that conducted by (Mulyady, Waluyo, \& Risdayanti, 2016) about blood pressure in post-stroke patients blood pressure values were obtained from 47 patients, $57.5 \%$ had hypertension, $17 \%$ had normal

blood pressure and $25.5 \%$ had hypotension.

The depression in ischemic stroke patients will result a slow rehabilitation process, low quality of life and increased mortality (Oros, Popescu, Iova, Mihancea, \& Iova, 2015). Severe depression results in the appearance of prolonged, excessive feelings of helplessness which increases the risk of suicide. Stroke sufferers who are depressed have a longer rehabilitation time than stroke sufferers without depression (Ramos-Lima, Brasileiro, Lima, \& Braga-Neto, 2018).

One of the efforts that can be done in decreasing depression is through psycho-education. Based on the results of the study (Espahbodi, Hosseini, Mirzade, \& Shafaat, 2015), psycho-education was effective to be carried out to reduce the level of anxiety and depression. Supported by the results of the research conducted by (R. Casanas et al., 2015), psycho-education is an effective therapy in treating depression in adults, since it reduces symptoms of depression and can prevent the occurrence of depression in primary care patients.

Psycho-education is an education/education that is carried out through an interactive process that encourages learning using a psychological concept approach. Learning is a media to add new knowledge, attitudes and skills through strengthening certain practices and experiences (Potter, Perry, Stockert, \& Hall, 2014). The results of the study (Hadidi, 2016) psycho-education can reduce blood pressure due to a good level of knowledge, effective coping, good adherence, so that it affects the physiological aspects.

\section{MATERIALS AND METHODS}

The design of this study used quasi-experiment with a pre and post control group design approach. The population of all ischemic stroke patients at Jemursari Islamic Hospital Surabaya was 100 people. The samples were 32 respondents. The sampling technique was simple random sampling. This research was conducted on 18 March to 30 April 2019 in the Islamic Hospital Jemursari Surabaya. The depression instruments used were questionnaires, Depression Anxiety Stress Scale (DASS) and blood pressure measured using sphigmomanometer. The intervention group was given psycho-education based on social cognitive theory for 15-30 minutes in 4 sessions and the control 
group was given intervention according to hospital standards. The social cognitive theory-based psycho-education was given to the patients in the form of modules that contain problem identification, health education, building expectations and evaluations. Module is a systemic process that is used as a learning media so that it can help the process of thinking and delivering the contents of the material provided and messages that must be considered. The analysis employed the test in the form of a paired t-test.

\section{RESULTS}

Depression

Table 1. Analysis of depression before and after administration of social cognitive theory-based psycho-education in the intervention group and the control.

\begin{tabular}{lllllllll}
\hline Group & & Mean & $\mathrm{N}$ & $\mathrm{SD}$ & $\mathrm{SE}$ & $\begin{array}{l}95 \% \\
\mathrm{CI}\end{array}$ & $\mathrm{t}$ & $\begin{array}{l}\mathrm{p} \\
\text { value }\end{array}$ \\
\hline Intervention & Before & 20.66 & 32 & 6.434 & 1.137 & & & \\
& After & 10.81 & 32 & 6.045 & 1.069 & 7.794 & 9.793 & .000 \\
& & & & & & - & & \\
& & & & & & 11.894 & & \\
\hline Control & Before & 18.59 & 32 & 5.599 & .990 & & & \\
& After & 18.16 & 32 & 5.892 & 1.042 & $\begin{array}{l}-.072- \\
0.947\end{array}$ & 1.752 & .090 \\
& & & & & & & \\
\end{tabular}

The results of the analysis in Table 1. show that the average depression before being given social cognitive theory-based psycho-education in the intervention group was 20.66 with a standard deviation of 6.434 and after the intervention was given a decrease in the depression average to 10.81 with a standard deviation of 6,045 . The average in the control group before being given action according to hospital standards found an average of 18.59 with a standard deviation of 7,448 and after being given action according to hospital standards it was found that the depression average decreased to 18.16 with a standard deviation of 5,892. Based on paired t-test obtained $\alpha<0.05$ and in the control group $\alpha>0.05$. This shows that social cognitive theory-based psycho-education affects the decline of depression.

\section{Blood Pressure}

Table 2. Analysis of blood pressure before and after administration of social cognitive theory-based psycho-education in the intervention group and the control.

\begin{tabular}{lllllllll}
\hline Group & & Mean & $\mathrm{N}$ & SD & SE & $95 \%$ CI & t & p value \\
\hline Systole & Before & 136.5 & 32 & 16.15 & 2.855 & & & \\
Intervention & & 3 & & 2 & & $6.206-14.356$ & 5.146 & .000 \\
& After & $\begin{array}{l}126.2 \\
5\end{array}$ & 32 & 8.328 & 1.472 & & & \\
& & 5 & & & & & & \\
\hline Systole & Before & 133.3 & 32 & 13.19 & 2.333 & & & \\
Control & & 1 & & 9 & & $-.440-2.377$ & 1.403 & .171 \\
& After & 132.3 & 32 & 13.52 & 2.391 & & & \\
& & 4 & & 6 & & & & \\
\hline Diastole & Before & 85.50 & 32 & 9.504 & 1.680 & & & \\
Intervetion & After & 81.31 & 32 & 6.473 & 1.144 & $2.366-6.009$ & 4.690 & .000 \\
\hline Diastole & Before & 85.16 & 32 & 7.582 & 1.340 & & & \\
Control & After & 85.75 & 32 & 7.984 & 1.411 & $-1.588-.400$ & -1.218 & .232 \\
\hline
\end{tabular}

Table 2 . shows that the average of systole before being given social cognitive theory-based psycho-education in the intervention group was 135.53 with a standard deviation of 16,152 and after intervention was found to decrease the mean systolic blood pressure to 126.25 with a standard deviation of 8,328 . The average in the control group before being given action according to hospital standards found an average of 133.31 with a standard deviation of 13,199 and after being given action 
according to hospital standards it was found that the average systolic blood pressure decreased to 132.34 with a standard deviation of 13,526. Based on paired t-test obtained $\alpha<0.05$ and in the control group $\alpha>0.05$. This shows that social cognitive theory-based psycho-education has an effect on reducing systolic blood pressure.

The results of table 2 . analysis show that the average of diastole before being given social cognitive theory-based psycho-education in the intervention group was 85.50 with a standard deviation of 9.504 and after intervention was found to decrease the average diastolic blood pressure to 81.31 with standard deviation 6.473 . The average in the control group before being given action according to hospital standards found an average of 85.16 with a standard deviation of 7,582 and after being given action according to hospital standards it was found that the average diastole increased to 85.75 with a standard deviation of 7.986. Based on paired t-test obtained $\alpha<0.05$ and in the control group $\alpha>0.05$. This shows that psycho-education based on social cognitive theory has an effect on reducing the diastole.

\section{DISCUSSION}

Social cognitive theory-based psycho-education is a therapy-modality delivered by professionals who integrate or synergize between psychotherapy and educational interventions which include problem identification, health education, building expectations and evaluations. The results of the study in the control group before and after the intervention given by nurses according to the standard hospital experienced a change in depression but not significant, this was evidenced in table 1.1 while in the intervention group there was a significant decrease in depression.

This phenomenon is shown in the results of the research conducted in Table 1.1 which proves that there is an influence of the provision of social cognitive-based psycho-education to decrease the level of depression in ischemic stroke patients with $\mathrm{p}$ value $=.000$. This is in line with the research conducted by (Zaini, 2014) stating that computerized based psycho-education can improve patient understanding of the problems suffered and can reduce the level of depression and be able to deal with problems related to the disease suffered. This is supported by the research conducted by (Tanaka, Ishikawa, Mochida, Kawano, \& Kobayashi, 2015) proving that psycho-education can reduce the level of depression. This is also supported by the research based on a meta-analysis conducted by (Yuniartika, Dwidiyanti, \& Mu, 2016) proving that psycho-education is proven effective in reducing depression levels in patients suffering from diabetes mellitus. A similar study based on a metaanalysis was also conducted by (Moreno-lacalle, 2017) proving that giving psycho-education can reduce the level of depression in patients who experience psychological health problems. This is supported by study conducted by (Tomita et al., 2018) proving that appropriate psycho-education in depressed patients is effective in reducing the level of depression because patients will be more able to control themselves in managing depression.

The education given through social cognitive theory-based psycho-education based on modeling and teaching will directly change the mindset of patients so that they can increase knowledge about diseases and the management of ischemic stroke. Supported by the second session of psycho-education which deals with management of self efficacy, depression and blood pressure based on social cognitive theory, patients can adopt self-management techniques that have been taught so they can accept the state of the disease and begin to motivate themselves to deal with ischemic stroke problems suffered. This is in accordance with the theory put forward by (Lukens \& Mc Farlane, 2004) that the goal of psycho-education is to develop and to improve patient acceptance of diseases or disorders suffered, increase patient participation in therapy and the development of adaptation mechanisms when patients face problems related to the disease suffered.

Social cognitive theory-based psycho-education focuses on educating participants to improve their ability to carry out rehabilitation, assist patients in developing sources of social support in carrying out rehabilitation, and carry out management of depression which includes relaxation and lifestyle arrangements. Thought (Brown, 2011) states that psycho-education will provide education or education by looking at potential threats or life development and to explain an individual to adapt critically to his life. After doing social cognitive-based psycho-education, ischemic stroke patients are more open to people around either family or friends and use existing sources of support so that patients are able to improve self-efficacy and patients are more confident in their abilities so that depression decreased and ischemic stroke patients become under-pressed. 


\section{Blood Pressure}

The employment of psycho-education based on social cognitive theory has a significant effect on changes in blood pressure. This phenomenon is shown in the results of research conducted in Table 1.2 which proves that there is an influence of the employment of social cognitive theory-based psycho-education to a decrease systole and diastolie of ischemic stroke patients, with a p value $=.000$ on systole and $\mathrm{p}$ value $=.000$ on diastole. This is in line with the research conducted by (Sudja \& Meirina, 2014) proving that the provision of psycho-education can improve the ability of pralans to handle hypertension. This is supported by research conducted by (Hadidi, 2016) proving that psychoeducation has a significant effect on reducing systole and diastole. This is supported by research conducted by (Levin et al., 2019) proving that giving psycho-education can improve the compliance of hypertensive patients in doing therapy and can reduce blood pressure. Several studies have shown that the management of hypertension with a non-pharmacological therapeutic approach including weight loss, alcohol, sodium and tobacco restriction, exercise and relaxation are mandatory interventions that must be performed on each therapy in hypertension patients (Smeltzer \& Bare, 2014).

The social cognitive theory-based psycho-education does not directly affect the blood pressure of ischemic stroke patients, but from social cognitive theory-based psycho-education, the patient's self efficacy increases and depression levels decrease so that patients become better and able to change the pattern or lifestyle of ischemics stroke patients to healthy lifestyle. This is what ultimately affects the physiological functions of the body, namely blood pressure drops and becomes more controlled. This is in line with the research conducted by (Aldcroft et al., 2011) stating the psycho-education for rehabilitation programs in patients with heart disease that have a positive effect on physical activity, reduce smoking and change unhealthy dietary habits.

Efforts to control hypertension as contained in modules and leaflets in social cognitive theorybased psycho-education are weight control, limitation of sodium and tobacco (smoking) and increased exercise and relaxation, so that this affects the blood pressure of ischemic stroke patients after psychoeducation intervention. In giving social cognitive theory-based psycho-education related to the management of blood pressure control, researchers motivate patients to reduce sodium and avoid foods high in fat and cholesterol and cigarettes. In addition, researchers also motivate ischemic stroke patients to increase activities such as walking in the morning or evening, cleaning the house and others.

\section{CONCLUSION}

Social cognitive theory-based psycho-education was effective to decrease depression and blood pressure of ischemic stroke patient and it is highly recommended for the patient in the rehabilitation phase.

\section{ACKNOWLEDGMENTS}

The author is thankful to respondents for their valuable information and their awareness to participate in this research.

\section{CONFLICTS OF INTEREST}

The author declares that they have no conflict of interest.

\section{REFERENCES}

AHA. (2015). The Stroke Family Caregiver. Retrieved from https://Www.Heart.Org/Idc/Groups/Strokepublic/@wcm/@hcm/Documents/Downloadable/Ucm_309723.Pdf.

Aldcroft, S. A., Physiotherapy, B., Taylor, N. F., Blackstock, F. C., Hons, B. P., \& Halloran, P. D. O. (2011). Psycho-educational Rehabilitation for Health Behavior Change in Coronary Artery Disease. Journal of Cardiopulmonary Rehabilitation and Prevention. https://doi.org/10.1097/HCR.0b013e318220a7c9

Brown, N. W. (2011). Psycho-educational Groups 3rd Edition: Process and Practice. New York: Routledge Taylor \& Francis Group.

Dewi, C. M., \& Darliana, D. (2017). Family Support And Depression Of Post-Stroke Patients. Idea Nursing 
Journal, 8(3).

Espahbodi, F., Hosseini, H., Mirzade, M. M., \& Shafaat, A. B. (2015). Effect of psycho education on depression and anxiety symptoms in patients on hemodialysis. Iranian Journal of Psychiatry and Behavioral Sciences, 9(1), 1-5. https://doi.org/10.5812/ijpbs.227

Guntur, M., \& Maria, F. (2017). The Relation Of Family Roles With The Levels Of Depression On Stroke Patient At Department Of Neurology Regional Public Hospital Sultan Syarif Mohammad Alkadrie Pontianak. Tanjungpura University.

Hadidi, K. (2016). The Effect of Psycho-education on Knowledge, Coping, Compliance, and Blood Pressure in the Elderly with Hypertension Using Roy's Adaptation Theory Model Approach. Journal Ners.

Hayulita, S., \& Sari, D. R. (2014). Factors associated with depression in post-stroke patients in the outpatient ward of the National Stroke Hospital (RSSN). Bukittinggi: Stikes Yarsi.

Hidayati, N., \& Violita, V. (2015). Family Role with Patient Motivation in Active Range of Motion. Journals of Ners Community, 6(1), 100-108.

Jauch, E. C., Saver, J. L., Adams, H. P., Bruno, A., Connors, J. J. B., Demaerschalk, B. M., ... Yonas, H. (2013). Guidelines for the early management of patients with acute ischemic stroke: A guideline for healthcare professionals from the American Heart Association/American Stroke Association. Stroke, 44(3), 870-947. https://doi.org/10.1161/STR.0b013e318284056a

Kaplan, H. I., \& Sadock, B. J. (2015). Kaplan-Sadock Sinopsis Psikiatri Ilmu Pengetahuan Prilaku Psikiatri Klinis (edisi-7). Tangerang: Binarupa Aksara.

Levin, J. B., Ph, D., Sajatovic, M., Rahman, M., Aebi, M. E., Tatsuoka, C., \& Ph, D. (2019). Outcomes of Psycho-education and a Text Messaging Adherence Intervention Among Individuals With Hypertension and Bipolar Disorder. Psychiatric Services in Advance, 1-5. https://doi.org/10.1176/appi.ps.201800482

Lukens, E. P., \& Mc Farlane, W. R. (2004). Psycho-education as Evidence-Based Practice: Considerations for Practice, Research, and Policy. Journal Brief Treatment and Crisis Intervention, 4.

Moreno-lacalle, R. C. (2017). Effectiveness of Psycho-education in Decreasing Depression As Co-Morbidity : A Meta-Analysis. Naresuan University Journal: Science and Technology 2017; (25).

Mulyady, E., Waluyo, J., \& Risdayanti, F. (2016). Blood Pressure in Patients with Post-Attack Stroke, 16(2), 41-45.

Oros, R. I., Popescu, C. A., Iova, S. O., Mihancea, P., \& Iova, C. A. (2015). Depression , activities of daily living and quality of life in elderly stroke patients. Http://Www.Hvm.Bioflux.Com.Ro/, 8(1), 24-28.

Potter, P. A., Perry, A. G., Stockert, P., \& Hall, A. (2014). Fundamentalof nursing Edition 7. Jakarta. Retrieved from Salemba Medika

R.Casanas, R.Catalan, R.Penades, J.Real, S.Valero, MA.Munoz, ... M.Casa. (2015). Evaluation of the Effectiveness of a Psycho-educational Intervention in Treatment-Nalve Patients with Antidepressant Medication in Primary Care: A Randomized Controlled Trial, 2015, 11.

Ramos-Lima, M., Brasileiro, I., Lima, T., \& Braga-Neto, P. (2018). Quality of life after stroke: impact of clinical and sociodemographic factors. Clinics, 73, 1-7. https://doi.org/10.6061/clinics/2017/e418

Riskesdas. (2018). Basic health research. Health research and development agency. Ministry of Health of the Republic of Indonesia.

Sari, M. L. (2017). The Relationship Between Self-Efficacy and Depression Events in Stroke Patients at Level II Hospital Dr. Soepraoen Malang. Universitas Brawijaya. Retrieved from http://repository.ub.ac.id/id/eprint/911

Smeltzer, S. C. O., \& Bare, B. G. (2014). Keperawatan Medikal Bedah Brunner and Suddarth's. Jakarta: EGC.

Sudja, N., \& Meirina. (2014). Psycho-education interventions increase the ability of pralence in the treatment of hypertension. Jurnal Ners, Vo.9.

Tanaka, S., Ishikawa, E., Mochida, A., Kawano, K., \& Kobayashi, M. (2015). Effects of Early-Stage Group Psycho-education Programme for Patients with Depression. Wiley Online Library (Wileyonlinelibrary.Com), (2011). https://doi.org/10.1002/oti.1397

Tomita, T., Kudo, S., Sugawara, N., Yasui-Furukori, Fujii, A., Tsuruga, K., ... Furukori, N. Y. (2018). Timing of psycho-education for patients with depression who were treated with antidepressants: when should patients receive psycho-education. Neuropsychiatric Disease and Treatment, 505-510.

Yuniartika, W., Dwidiyanti, M., \& Mu, M. (2016). Reducing depression level of diabetes mellitus patient by psycho-education by means of poster. Nternational Journal of Research in Medical Sciences, 4(8), 33483353.

Zaini, M. (2014). Management of care by using computer-based psycho-education to clients with mild depression. E-Journal WIDYA Kesehatan Dan Lingkungan, 1. 